RECOLLECTIONS OF A I.ONG PROFESSIONAL LIFE-1844 TO 1904.

BY LOMBE ATTHILL, M.D.,

EX-MASTER OF THE ROTUNDA HOSPITAL, DUBLIN; AND EX-PRESIDENT, ROYAL COLLEGE OF PHYSICIANS OF IRELAND.

I WAS bound as an apprentice in June, 1844, to Mr. Maurice Colles, at that time one of the surgeons to the Meath Hospital, Dublin. I was then only $16 \frac{1}{2}$ years old. It had not been intended that I should take a degree in Arts; but, finding that my classical education had been fairly good, Mr. Colles advised that I should enter Trinity College, Dublin, which I accordingly did; and, although this entailed the additional labour of doing for four years classical and mathematical work in addition to my medical studies, I undertook it willingly, and have always been glad that I followed the advice given by my master.

Mr. Colles was a truly good man, who devoted both time and money to good and charitable work. He was known as "Colles the Good" to distinguish him from his contemporary "Colles the Great"-he who first correctly described the fracture still known by his name. He was also a strict and most painstaking master. He required his apprentices to attend hospital every day both regularly and punctually; for myself, I do not think that from the day I joined the class to the final day of the examination for my diploma I was ever once absent, unless prevented by illness or during vacation.

From the first I was taught how to bandage, to draw teeth, and to bleed, and soon commenced case-taking; and at the end of my first session had gained such proficiency in these matters and such knowledge of fractures and the treatment of surgical cases of minor importance that Mr. Colles permitted me to go in for the Junior Surgical Prize, open to pupils of not more than two years' standing. I failed on this occasion. All the other candidates were second years men. Next year I gained it easily. I mention these trifles as they serve to contrast the present system, under which clinical teaching is virtually prohibited till the third year of study, with that which existed seventy years ago. But my hopes of entering the profession were well nigh extinguished before my third year of study was completed by my father's unexpected death (January, 1847). He was a very pious man, a clergyman of great ability. He had been Second Wrangler in his year, and subsequently a Fellow of Caius and Gonville College, Cambridge. His income dying with him, I feared lack of means would render it impossible for me to serve out my five years' apprenticeship. As foon as I had completed the three years' curriculum at that time required by the Colleges of Surgeons both of England and Ireland, I begged my master to permit me to present myself for examination for the diploma of the latter college, and, passing it successfully, found myself in $\mathrm{July}, 1847$, a full-blown surgeon at the immature age of $19 \frac{1}{2}$. Ever since have I regretted this cutting short of my regular period of study.

Fortunately for me, my relatives enabled me to ceside in Dublin during the following winter, so as to complete my university course. During that winter I filled the post of Assistant Demonstrator in the Park Street School of Medicine, which has long since ceased to exist. I also, as an ex-apprentice, was permitted to continue my attendance in the clinical class at the Meath Hospital, while I read steadily for my Medical and Arts degrees. It was not till Shrove Tuesday, 1849, that these were conferred, and at that time I was engaged in practice in the country.

The Dublin School of Medicine had at the time I joined the profession an excellent reputation, specially for the teaching of anatomy. Professor Harrison, in the school of the University of Dublin, and Mr. Power, in that of the College of Surgeons, were anatomists of deservedly high repute, and in the other Dublin schools the teaching of anatomy was good. Indeed, so highly was a knowledge of anatomy esteemed, that a good anatomist, though deficient in other subjects, was but seldom rejected by the examiners for the Diploma of the College of Surgeons, which at that date was the only qualifi. cation held by the great majority of the provincial practitioners. The clinical teaching of surgery was in like manner generally good, but that of medicine, in most hospitals, neglected, the attendance of students in the medical wards not being enforced. Of course there were exceptions to this. Graves and Stokes at the Meath Hospital were notable exceptions. The latter distinguished man became later on my kind friend, as he was then my esteemed teacher.

Students dissected and attended hospital from the day they commenced their studies, and now at the end of $\mathrm{my}$ life, and after taking an active part as a member of the General Medical Council in formulating first the four year and subsequently the five year scheme now in force, and having watched the working of these systems for years, I am satisfied that the relegation of anatomy to the secondary position it now holds in the five year scheme, and the postponement of hospital attendance till a later period of study are grave mistakes.

There were many eminent men amongst the Dublin surgeons in those dass, but their methods would now be looked upon with horror, and, contrasted with bloodless operations of to.day, would justly be considered dreadful.

When anaesthetics were unknown, patients had always to be held, often strapped, down to the table while operations proceeded, and the groans and screams, specially in the case of women and children, were most distressing to hear. Instead of the deliberate care with which operations are now performed, surgeons vied with each other as to which would perform an operation in the shortest time. Much blood was lost. A tourniquet would be applied were a limb to be amputated, but beyond this no attempt would be made to temporarily arrest haemorrhage; the bone being sawn through, then the arteries would be ligatured with silk, and the stump dressed. But the mortality, even after the simplest operations, was great, and sloughing of the integu. ments quite common; even simple incisions seldom healed by "first intention." I have a vivid recollection of having seen two operations for strangulated hernia performed, I think on the same day, both patients being healthy men; both were dead a few days later. Cutting for the stone, too, was a not uncommon operation, and very frequently fatal.

On one occasion I saw the bladder opened from above the pubes with the view of removing a portion of a gum-elastic catheter which had broken off while being passed by the patient himself and retained in the bladder. That patient died a day or two sub. sequently. Contrast this with the results of the operation for the enucleation of the prostate gland now so frequently and successfully performed, and the present generation of surgeons will realize the incalculable benefits conferred on them and the whole human race by Lister.

When I was a student infectious cases were admitted into the medical wards of the Meath Hospital. The fever wards, as they were termed, were on the top story; the story below that was allotted for the recep tion of chronic cases; on the lower story were the accident wards, etc. Cases of typhus fever, of scarla. tina, and even of small.pox, were frequently admitted. Wonderful to say, I have no recollection of these diseases being communicated to patients in the surgical wards. Of course, all this has long since been changed.

Then as to the nurses. Medical and surgical alike were virtually untrained, and many of them illiterate. There were no regular night nurses. The nurses were not dressed in uniform in any Dublin hospital, nor even supplied with dresses. There was one to each ward, who was responsible for the patients by night as well as by day. These women were kindhearted and attentive, and I believe that-at least in the Dublin hospitals - the patients were fairly well cared for and contented. In cases where patients were delirious, 
or required special watching at night, some respectable' old woman of the charwoman class would be engaged to act as night nurse.

During the winter of 1847-8, while acting as demonstrator, as already mentioned, I was appointed to the Fleet Street Dispensary-an institute, supported by voluntary contributions, for the good of the sick poor, who were visited at their own houses, as well as prescribed for at the institution. No member of the staff received any remuneration; on the contrary, each of us had to undertake to find two new subscribers of $£ 1$ 1s. each, or to pay these subscriptions out of our own pockets. I gladly accepted the appointment on these terms.

The condition of the sick poor in Dublin was at this date and for many years subsequently truly appalling. The famine, due to the failure of the potato crop, had lasted for a year and a half. In all parts of the country there was the greatest distress, and in remote districts absolute starvation; hundreds died of starvation, thousands of "famine fever," as it was termed, typhoid not having been recognized or known, while typhus in its worst form was epidemic; large quantities of Indian meal was imported by the Government, but railways did not then exist in Ireland, and means of transport were wanting. Whole districts were depopulated by famine and fever, thousands emigrated to America, while the towns and cities were crowded by hosts of starving men, women, and children, who thronged the streets begging for food. Some sought employment which could not be obtained, while hospitals and poorhouses were filled to excess. Temporary hospitals, known as the "fever sheds," were erected outside the city, but even these failed to supply sufficient accommodation for the famine-stricken multitude of sick. What the work of the dispensary doctor who laboured amongst this poverty-stricken mass of humanity was, when overtaken by disease, may be imagined but can hardly be described.

The tenement houses in which the poor lived were crowded from attic to cellar. I have known four families each consisting of several individuals, living in one small room, a corner allotted to each family, without a stick of furniture amongst them. One instance I never shall forget. I narrate it to give some idea of the hopelessness of the task devolving on the medical man at this sad period. My district embraced the lowlying slums contiguous to the River Liffey. One day I received a ticket directing me to visit a woman in one of these streets, not of the worst class. Calling at the address given, I was told that the patient lived in the "kitchen," and as there was no communication between the house proper and the so-called kitchen I had to go out of the front door and down into the area to gain entrance. There I found the woman in a veritable cellar, into which neither air or light could enter save through the door. Her case was one of typhus fever, so I gave her an order for admission to the fever hospital. Before leaving I was asked to see another patient in the "back room," which I did. As it was pitch dark there they lit a candle; both these roqms were below the high-water mark of the river, which was but a few yards distant. The outer cellar was bad enough, but the back one was frightful. The walls, which were wholly below the level of the ground, had never been plastered; down them trickled little streams of water, the floor was saturated with damp, the air foul, and on a kind of bed raised a few inches from the floor lay a girl with small-pox. It is not a matter of surprise that the lives of several of the doctors engaged in this practice were lost from diseases contracted in these wretched dens.

Typhoid was not at this time recognized as a distinct and special disease. Typhus was well known and always prevalent in the large towns, but most of the other cases of continued fever were called "gastric," and a great controversy arose as to the nature of the so-called "famine fever" which raged from 1848 to 1855, one of its more pro. minent features being its tendency to relapse even when the patient seemed to have nearly reached convalescence, and from this it was not infrequently spoken of as "relapsing fever." Much interest was taken on the Continent as to its true nature, and two members of the Academy of Medicine were sent from Paris with introductions to Dr. Stokes to investigate the disease in Dublin. He received them with great courtesy, but as neither of these gentlemen could speak one word of English, I do not think their visit was productive of much good, but it gave rise to an incident for the truth of which I can vouch.

After taking the French physicians to see the patients suffering from this fever in the Meath and other hospitals, Dr. Stokes, at their request, took them to the slums from whence these cases came, and during their investigations they found themselves in a yard, in which numerous pigs were kept, while in what had been a stable-loft the owner and family resided, a number of cows being stalled under them. There was a huge heap of manure in the yard, and the room in which the family lived reeked with the stench from it and the cattle under them, as, indeed, did the whole yard. The Frenchmen were horrified, and, turning to Stokes, said that no doubt in such a place fever cases wust abound. Dr. Stokes accordingly asked the owner if there was much fever about him. "No," he replied, and, calling his man, asked him the same question, to be told that he knew of none. The further astonishment of the French doctors was great, and they asked if any explanation could be given for this immunity from fever in such a place. Dr. Stokes, who had a vein of humour in his composition, repeated their question to the owner, who scratched his head, thought for a moment, and replied, "Faith, your honour, I don't know, barring it's the stink keeps it. away." The doctors did not carry their investigations. further.

As it was impossible for me to continue to reside in Dublin, holding only a post to which no salary was attached, I was obliged to seek an opening in the country, and a few days after my twenty-first birthdaywas appointed surgeon to a very poor dispensary district in King's County, on the verge of the great bog district.

The village of Geashill, in which I had to reside, was poor indeed; but, for an Irish village, clean. The district had previously been served by a doctor who lived five miles off. I was the first to reside in the district, and there was no house for me to live in, so I had to put up with lodgings in the only house in the village where such could be obtained. This was a long, low, one-storied thatched cottage. There were just. four rooms, all mud-floored. The kitchen, in the centre, was the family day room (they slept in windowless loft over it, reached by a ladder, which 1 was never permitted to ascend). Off the kitchen to the right was a small room in which were for sale a: limited supply of groceries and unlimited supply of whisky. Opening off the kitchen to the left was my sitting-room, with a hard, dry earth floor, the centre covered with matting. It was a fair-sized room, about $16 \mathrm{ft}$. by $14 \mathrm{ft}$. Off it was my bedroom; it was only $7 \mathrm{ft}$. by $14 \mathrm{ft}$. Its floor, also of earth, was in wet. weather very damp and soft. To enter or leave my apartments, I had to go through the kitchen, and this on market days was thronged with customers. Sometimes one of these would open my door and look in. but I was always treated with great respect and courtesy, and I spent the winter months from January 1st, 1849, very contentedly there, poor though the place was. I had plenty to do amongst the poor; and had to read for my M.B. degree, which I was not. yet qualified to go up for. I passed the examination for it early in the spring, and later on moved into a house some little distance from the village.

The district was so large I had to keep a horse. I was paid a salary of $£ 80$ a year, and got a little private practice, but as there were virtually no. resident gentry, and as in consequence of the famine the farmers were very poor, it is not surprising that. this only produced $£ 40$ that year; indeed, I doubt even had I remained, if I could have made much more in that district. But before the second year had expired I was offered the appointment of medical referee to $a$. well-known insurance company in Dublin. I with 
some hesitation accepted that, not with the hope that I should succeed in getting into practice in Dublin, but that I might have the opportunity of improving myself in the knowledge of my profession, being painfully aware of my deficiencies, and I always believe that I owed such success as I subsequently attained to my determination to improve my education in every way, and to the last day of my over fifty jears of active practice I tried to learn something in every possible way and from everybody.

An amusing incident occurred to me while at Geashill. Late at night I received a ticket requiring me to visit a woman in labour who resided a mile from my house. I found the patient to be a robust woman, aged about 35 , primipara. Os nearly fully dilated, head just entering the brim, after a very tedious first stage. I had never seen the forceps used, and had been taught never to apply them unless I could feel the child's ear. I therefore told the friends that they must have patience, and believing that probably many hours would elapse ere I could deliver her, and not caring to spend the night in a wretched cabin, I said that she was going on well, and that I would come again if sent for. But first discovering that the bladder was greatly distended, I emptied it, using for the purpose a short silver catheter. So home I went and to bed, expecting to be sent for during the night; but I was not, and fearing I should be blamed for leaving her, I rode off to visit her quite early in the morning. My anxiety was soon dispelled, for before I could dismount a woman rushed out, exclaiming, "God bless your honour! Sure, you were no time gone, but the real pains came on and she was well in no time." I went my way rejoicing and forgot all about the case; but about three inonths after a man rode up to my house, saying he wanted me to go and see his wife, who was a long time in labour. I learned that he lived some miles off, outside my district, but as he offered to pay a fee I went with him. The patient was very young, looked delicate, and was quite exhausted by a very protracted labour, certainly much more than of twenty-four hours' duration. The pelvis was small, and the child's head was impacted in it. I believed the child to be dead, and told them that though I could deliver her the child would be dead. On my saying this there was a great outcry, and one woman exclaimed : "Why, we heard you had a silver horn, that you would point it at the child's head, and that it would follow it." Then it dawned on me that my catheter had been supposed to be an "enchanted horn," so my reputation was as quickly blighted as it had sprung up.

About this time I assisted an old practitioner residing in a neighbouring town in an operation which I can never forget. He deservedly enjoyed the reputation of being a good physician, but of operative surgery he was profoundly ignorant. The patient waís an old man, aged about 65 , living in a wretched hovel in the middle of a bog. His wife, as old as himself, was the only other occupant of this miserable dwelling, which consisted of just one room. Of course, antiseptics were unknown at that time, and even of water there was but little, and that was taken from a neighbouring bog hole. As for such things as towels, etc., there were none. The case was one of strangulated hernia of several days' standing, and the old man was too exhausted to permit of his removal to hospital, the nearest being many miles distant.

The preliminary arrangements were simple in the extreme; in fact, there were none. The operation was performed as the old man lay in his extremely dirty old bed-nothing on which had known what washing was for many a long day. The old wife, the operator, and myself were the only persons present.

My friend proceeded to operate without delay. I observed from the first that he was very nervous and that his hand trembled sadly. He succeeded, however, in exposing the sac satisfactorily, but on his proceeding to divide the stricture he punctured the sac. With escape of gas, the intestines collapsed, and were easily returned into the abdomen. The wound was then closed, and the patient left to the care of his ignorant old wife. I do not think that the doctor and
I exchanged a word as we picked our way across the bog. I know I took it for granted that the patient would soon be a corpse.

A week elapsed ere I was again near the town where the old doctor resided; then I met him in the street and asked about the patient. "Oh," he replied, "he is quite well and walking about!"

I had one private midwifery case during my eighteen months' stay in the country, and it, too, had a ludicrous side.

The patient was a very young lady, and it was her first confinement. Her labour was easy and natural and convalescence rapid, so on her seventh day I allowed her to be up on the sofa, and I called that afternoon to see how she got on. It was a bright, warm, sunny day, but I found my patient wrapped up in blankets, lying before a huge fire, very hot and flushed. Opposite her sat the monthly nurse-a fat, pompous old woman, ignorant, and illiterate, and who had always treated me with little courtesy and indeed, with hardly veiled contempt; in truth, though I was 22, I did not look 18. On her lap lay the baby, well swathed up. As I was leaving my patient said, "I am so hot, may I have a drink of water?" "Yes, of course," was my reply, whereupon the old nurse rose slowly from her seat, and, facing me, said, "No patient of mine shall taste anything cold till the ninth day," and then majestically sat down again. I was extinguished, and the water was not given!

(To be continued.)

\section{THE ROYAL COMMISSION ON THE POOR LAWS AND RELIEF OF DISTRESS.}

THE MINORITY REPORT.

WITH SOME OBSERVATIONS ON SCHOOL CLINICS.

Dr. E. VIPONT Brown recently read a paper before the South Manchester Division of the British Medical Association on The Medical Profession : Its Present and Its Future. After discussing the position of the Poor Law medical officer, the condition of out-patient departments, and the advantages and disadvantages of provident dispensaries and sick clubs, he passed on to consider the report of the Poor Law Commission, addressing himself mainly to the recommendations of the Minority Report, upon which he made the following observations:

The Minority Report.

That report suggests that the care of the poor should be entrusted to well-salaried whole-time medical officers acting under the chief medical officer of the county or county borough, who would be a very highly paid and responsible official requiring organizing capacity and administrative ability. Under his direction the medical service would comprise three branches, each with a staff of officers. Thus there would be :

1. The Clinical and Domiciliary Staff, to do the work now done by the parish doctors, by the physicians to the out-patient departments of hospitals, by the provident dispensary doctors, by the club doctors, and by the sixpenny doctors.

2. The Institutional Staff, to look after the various public hospitals, convalescent homes, sanatoriums, and other medical institutions.

3. The Sanitary Staff, to do the work now done by the medical officers of health. Each of these branches might equally well lead to the coveted position of chief medical officer of the county or county borough, who would thus be at the head of an efficient staff of medical men, all of whom would be in the position of civil servants, and only dismissible with the consent of the central health authority. Indeed, this excellent scheme suggests a Minister of Health with a seat in the Cabinet.

The whole idea underlying this scheme set forth in the Minority Report is radically different from that underlying our present methods of treating the poor. Instead of making a "lightning diagnosis" and hurrying our patients away well satisfied with a " bottle," it will be the 